\title{
EFFECTS OF ACYL GROUPS AND ETHANOL RATIOS ON LIPASE-CATALYZED REGIOSELECTIVE DEACYLATION IN PERACYLATED METHYL GLYCOPYRANOSIDES
}

\author{
Kwo-Feng Hsiao ${ }^{\mathrm{a}}$, Fang-Lin Yang ${ }^{\mathrm{b}}$, Shih-Hsiung $\mathrm{Wu}^{* \mathrm{~b}}$ \\ and Kung-Tsung Wang*a,b \\ a Department of Chemistry, National Taiwan University and \\ $\mathrm{b}$ Institute of Biological Chemistry, Academia Sinica, Taipei, Taiwan. R.O.C.
}

Summary : Regioselective ethanolysis of peracylated methyl $\beta, \alpha$-D-glucopyranoside and methyl $\alpha$-D-mannopyranoside in anhydrous organic solvent (n-hexane/EtOH $=99 / 1$ ) could afford 6-OH derivatives exclusively by Candida rugosa lipase (CRL). No $4 \rightarrow 6$ acyl migration was observed in such an anhydrous solvent system. Substrates with propanoyl groups were more reactive than with acetyl groups on CRL-catalyzed reactions.

\section{Introduction}

Lipases have been proven to be effective for synthetic transformations with high selectivitics by organic chemists 1 and successfully applicd in carbohydrate chemistry 2 especially in nonpolar organic solvents. It is well-known that the catalytic efficiencies and selectivities of lipase are affected by both substrate structure and solvent hydrophobicity ${ }^{3}$. Regioselective protection of carbohydrate is a considerable challenge because the presence of multiple hydroxyl groups of similar reactivity. Partially acylated sugars are of great importance and widespread application in carbohydrate chemistry 4 . In previous work. partially acylated sugars have been prepared by lipase-catalyzed regioselective deacylations 5,6 and acylations 6,7 .

One disadvantage was that in the enzymatic reaction in a buffer system, partially acetylated glycopyranosides from the lipase-catalyzed reaction undergo acetyl migration 8 so that column chromography is necessary to seperate the mixtures.

To the best of our knowledgement, no studies have been carried out to elucidate the effect of substrate structure and ethanol ratios on the catalytic efficiency of lipase-catalyzed reaction. Modifying both the substrate structure and the reaction medium were employed to 
optimize enzyme-catalyzed procedure. CRL (Candida rugosa lipase) catalysis could be controlled by the hydrophobicity of the solvent and the structure of the acyl moiety 9 . Acetyl migration could be ignored in the solvent with low polarity and without salts. We, therefore, studied the modification of this enzyme-catalyzed procedure, changing the solvent hydrophobicity by adjusting ethanol ratios in n-hexane, and changing the substrate structure by regulating the chain length of acyl groups on monosaccharides to develop a novel, efficient and simple methodlogy to obtain $6-\mathrm{OH}$ sugar acetates via "substrate engineering" and "medium engineering".

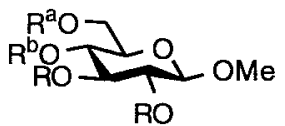

$\mathbf{1 a}, \mathbf{b}, \mathbf{c}, \mathbf{d}, \mathbf{e}, \mathbf{f}$

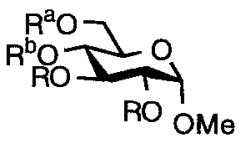

2a,b,c,d,e,f

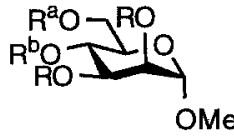

3a,b,c,d,e,f a, $R=R^{a}=R^{b}=A c$

b, $R=R^{b}=A c, R^{a}=O H$

c, $R=R^{a}=A c, R^{b}=O H$

d, $R=A C, R^{a}=R^{b}=O H$

e, $R=R^{a}=R^{b}=P r$

f, $R=R^{b}=\operatorname{Pr}, R^{a}=O H$

$\mathrm{Ac}=\mathrm{C}(\mathrm{O}) \mathrm{CH}_{3}$

$\mathrm{Pr}=\mathrm{C}(\mathrm{O}) \mathrm{CH}_{2} \mathrm{CH}_{3}$

\section{Experimental Section}

${ }^{1} \mathrm{H}$ NMR and ${ }^{13} \mathrm{C}$ NMR spectra were recorded on a Rruker AM-400 instrument in $\mathrm{CDCl}_{3}$ and are reported in $\delta$ units relative to $\mathrm{CHCl}_{3}$ fixed at $7.24 \mathrm{ppm}\left({ }^{1} \mathrm{H}\right)$ and $77 \mathrm{ppm}$ $\left({ }^{13} \mathrm{C}\right)$. Analytical TLC was performed on precoated MERCK $60 \mathrm{HF}_{254}$ silica gel G plates ( $0.25 \mathrm{~mm}$ thicknes); spots were visualized by spraying with $5 \%$ sulfuric acid in ethanol and heated on hot plate. Column chromatographies were performed with Merck 60 silica gel (70-230 mesh) by Still method (flash chromatography). HPLC analyses were performed on a Hitachi L-6200A intelegent pump system. The analyses were carried out on a reversephase Nucleosile C-18 column (10um; $4.6 \times 250 \mathrm{~mm}$ ), with the solvent mixture of $\mathrm{CH}_{3} \mathrm{CN}$ and $\mathrm{H}_{2} \mathrm{O}$; the flow rate was $1 \mathrm{~mL} \cdot \mathrm{min}^{-1}$, and dectection was performed at $214 \mathrm{~nm}$.

CRL (Candida rugosa lipase) was purchased from Sigma Chemical Co. In all experiments, the lipase was used directly from the bottle without any prior pretreatment. All organic solvents were of analytical grade and, prior to use, were stored on $4-\AA$ molecular sives (Merck) (about $1 \mathrm{~g}$ of molecular sieves $/ 5 \mathrm{~mL}$ of solvent) at room temperature. The molecular sieves employed in this work was activated in an oven for 48 hour at $120^{\circ} \mathrm{C}$. All other reagents not mentioned were used directly from the bottles.

\section{Structure Determination :}

All the structure determination were performed by NMR and the position of deacylation in all enzymatically prepared compounds was established by ${ }^{1} \mathrm{H}$ NMR and ${ }^{13} \mathrm{C}$ NMR which compared the corresponding fully peracylated sugars. At the 6-position, the chemical shift of $\mathrm{CH}_{2}$ at the deacylation site would show an up-field shift $0.5 \sim 0.7$ ppm relative to the corresponding acylation site.

1. General Procedure for CRL-Catalyzed Hydrolysis of peracetylated sugars 1a, 2a and 3a in Phosphate Buffer (Table 1.) 
The substrate $(1 \mathrm{~g})$ was stirred in a $50 \mathrm{ml}$ phosphate buffer solution $(0.1 \mathrm{M} \mathrm{pH} \mathrm{7.0)}$. After $2 \mathrm{~g}$ enzyme is added, the mixture was stirred at room temperature, and the reaction is monitored by TLC. The reaction was kept at $\mathrm{pH} 7.0$ with $1 \mathrm{~N} \mathrm{NaOH}$. Once the substrate was consumed, the reaction was terminated and extracted by EtOAc $(3 \times 100 \mathrm{~mL})$. Then, all the products were purified by column chromatography with the eluent from n-hexanediethyl ether $(2: 8)$ to diethyl ether.

\section{General Procedure of CRL-Catalyzed Ethanolysis of Peracetylated Sugars 1a, 2a and 3a in Organic Solvent}

The substrate $(181 \mathrm{mg}, 0.5 \mathrm{mmol})$ was suspended in $10 \mathrm{~mL}$ solvent mixture (nhexanc-cthanol, 99:1). After $0.5 \mathrm{~g}$ enzyme was added, the mixture was shaken at $240 \mathrm{rpm}$ at $30^{\circ} \mathrm{C}$, and the reaction was analyzed by HPLC for the conversion by withdrawing $0.1 \mathrm{~mL}$ reaction solution in each interval, then filtration of the enzyme and evaporation of the solvent in a stream of nitrogen. The crude compounds were analyzed quantitatively by dissolving in $0.2 \mathrm{~mL}$ acetonitrile for HPLC. The analysis from HPI.C. was carried out in the program, $1 \mathrm{~mL} \cdot \mathrm{min}^{-1} 20 \% \mathrm{CH}_{3} \mathrm{CN}$. Once the required extent of conversion was reached. the enzyme was filtered off, washed with $\mathrm{Et}_{2} \mathrm{O}$ and the solvent removed by evaporation and the reactions stopped after $48 \mathrm{~h}$. If necessary, the hydroxyl products and the unreacted tetraesters were separated by chromatography on a silica gel column and with hexane-cthyl acetate $(1: 1)$ as a eluent.

3. General Procedure of CRL-Catalyzed Ethanolysis of Perpropanoylated Sugars 1e, 2e and 3e in Organic Solvent

The substrate $(209 \mathrm{mg}, 0.5 \mathrm{mmol}$ ) was dissolved in $10 \mathrm{ml}$, solvent mixture ( $\mathrm{n}$ hexane-ethanol, 99:1), and process as above (2). The analysis by HPLC was carried out at 1 $\mathrm{mL} \cdot \mathrm{min}^{-1} 42 \% \mathrm{CI}{ }_{3} \mathrm{CN}$. If necessary, the hydroxyl products and the unreacted tetraesters were separated by chromatography on a silica gel column and with hexane-ethyl acetate (2:1) as a cluent.

Table 1. CRL-Catalyzed Hydrolysis of Peracetylated Methyl Glycopyranosides in a Phosphate buffer. a

\begin{tabular}{cccccc}
\hline entry & substrate & reaction time $(\mathrm{h})$ & \multicolumn{3}{c}{ products (yield, \%) } \\
\hline 1 & $\mathbf{1 a}$ & 12 & $\mathbf{1 b}(30)$ & $\mathbf{1 c}(11)$ & $\mathbf{1 d}(58)$ \\
2 & $\mathbf{2 a}$ & 2 & $\mathbf{2 b}(91)$ & $\mathbf{2 c}(3)$ & $\mathbf{2 d}(3)$ \\
3 & $\mathbf{3 a}$ & 2.5 & $\mathbf{3 b}(94)$ & $\mathbf{3 c}(3)$ & $\mathbf{3 d}(2)$ \\
\hline
\end{tabular}

$a$, Reaction conditions are described as in the experimental section. b, Isolated yicld.

\section{Results and Discussion :}

In general, lipases are well-known to catalyze hydrolysis of peracetylated carbohydrates in aqueous solutions with high regioselectivities ${ }^{2}$. Several commercial lipases were screened and are listed in Table 1..To effect lipase-catalyzed regioselective hydrolysis of peracetylated methyl glycosides 1a, 2a and 3a, Candida rugosa lipase (CRL) was a powerful catalyst for the preparation of partially acetylated monosaccharides with one hydroxyl group on primary position in phosphate buffer $(0.1 \mathrm{M}, \mathrm{pH} 7.0)$. CRL is well- 
known as a highly useful catalyst for regioselective reactions in organic solvents 1,10 and the catalytic efficiency can be changed as the chain length of acyl groups changed $9,5(a), 11$. Unfortunately, some drawbacks are that 4-OH derivatives were formed from $6-\mathrm{OH}$ derivatives via 1,3-acetyl migration 12 in the buffer solution and, furthermore, 4,6-OH derivatives are generated from $\mathrm{CRL}$-catalyzed cleavage of 6-O-acetyl group of 4-OH derivatives ${ }^{8}$. It was therefore necessary to purify the mixtures by column chromotography. This moved us to adjust the reaction system to avoid the acetyl migration.

Table 2. CRL-Catalyzed Ethanolysis of 3e in Various Ratio of Ethanol in n-Hexanea

\begin{tabular}{|c|c|c|c|c|c|}
\hline \multirow[b]{2}{*}{ entry } & \multirow{2}{*}{$\begin{array}{c}\text { solvent } \\
\text { ratio of ethanol } \\
\text { in n-hexane (\%) }\end{array}$} & \multicolumn{3}{|c|}{ product yield (\%) } & \multirow{2}{*}{$\begin{array}{c}\text { initial rate } \\
10^{3}\left(\mathrm{mM} \cdot \mathrm{h}^{-1}\right)\end{array}$} \\
\hline & & $5 \mathrm{~h}$ & $9 \mathrm{~h}$ & $24 \mathrm{~h}$ & \\
\hline 1 & 0.5 & 41.0 & 41.7 & 43.3 & 18 \\
\hline 2 & 1 & 53.4 & 67.2 & 84.0 & 11 \\
\hline 3 & 2 & 48.4 & 59.5 & 72.6 & 10.2 \\
\hline 4 & 5 & 22.7 & 36.5 & 66.4 & 4.4 \\
\hline 5 & 10 & 10.3 & 19.1 & 41.8 & 1.2 \\
\hline 6 & 20 & 2.1 & 5.1 & 12.4 & 0.2 \\
\hline 7 & 50 & 0 & 0 & 0.3 & 0 \\
\hline 8 & 100 & 0 & 0 & 0 & 0 \\
\hline
\end{tabular}

a, Reaction condition: each substrate $(0.5 \mathrm{mmol})$ was dissolved in $10 \mathrm{ml}$ of anhydrous solvent mixture (listed in the column 2), followed by addition of $C$. rugosa lipase $(500 \mathrm{mg}$ ). The further analysis was described as the experimental section. $\mathrm{c}$, The initial rate is determined in ctalyzed reaction for $0.5 \mathrm{~h}$.

Compound 3e was selected as a model substrate and the reaction medium was composed with $n$-hexane and ethanol as an acyl acceptor. Perpropanonylated methyl $\alpha-D-$ mannopyranoside $3 \mathbf{e}$ could be dissolved in all the solvent mixtures tested. CRL catalysis was performed for the examination of the effect of ethanolysis in different ratio between ethanol and $n$-hexane, the results shown in Table 2 .

As expected, CRL catalyzed regiospecific ethanolysis was on the 6-acyl group and only one product was produced without any other compounds monitored from TLC and HPLC. The catalytic efficiency of CRL-catalyzed ethanolysis is highly dependent on the hydrophobicity of the reaction medium. So, the solvent mixture (n-Hexane/FtOH =99/1) showed the most suitable reaction medium and was selected for futher investigation. 
The general reaction condition was established from Table 2., and two different chain lengths of acyl groups were introduced methyl $\beta$ or $\alpha$-D-glucopyranoside and methyl $\alpha$-D-mannopyranoside for the further study. The reaction progress were analyzed by HPLC ${ }^{13}$ and all the reactions were stopped after incubation for 48 hours. All the results and typical procedure are shown in Table 3., only 6-OH derivatives were found without any other products. The structure of products were determined by ${ }^{1} \mathrm{H}$ and ${ }^{13} \mathrm{C}$ NMR spectra compared to the established data from partially acetylated methyl glycopyranosides in the related work $5 \mathrm{e}, 5 \mathrm{~g}, 6 \mathrm{a}$.

Table 3. CRL-Catalyzed Regiosclective Ethanolysis of Pcracylated Methyl Glycopyranosides in Anhydrous Media ${ }^{\mathrm{a}}$

\begin{tabular}{cccccc}
\hline & & & \multicolumn{2}{c}{${\text { yield }(\%)^{\mathrm{b}}}^{2}$} & \multicolumn{2}{c}{ initial rate $^{\mathrm{d}}$} \\
entry & substrate & product & $24 \mathrm{~h}$ & $48 \mathrm{~h}$ & $10^{3}\left(\mathrm{mM}^{\left.-\mathrm{h}^{-1}\right)}\right.$ \\
\hline 1 & $\mathbf{1 a}$ & $\mathbf{1 b}$ & 38 & $84 \mathrm{c}$ & 9.6 \\
2 & $\mathbf{1 e}$ & $\mathbf{2 f}$ & 71 & 100 & 35 \\
3 & $\mathbf{2 a}$ & $\mathbf{2 b}$ & 100 & - & 30.4 \\
4 & $\mathbf{2 e}$ & $\mathbf{2 f}$ & 100 & - & 88.8 \\
5 & $\mathbf{3 a}$ & $\mathbf{3 b}$ & 60 & 94 & 21.6 \\
6 & $\mathbf{3 e}$ & $\mathbf{3 f}$ & 73 & 100 & 69.1 \\
\hline
\end{tabular}

a, The acylated compounds were chemically synthesized using acid anhydride and perchloric acid as the catalyst. Reaction conditions are as described as the experimental section. $b$, The yield was calculated by integration peak area from HPLC. $c$, Additional $0.1 \mathrm{~mL}$ ethanol added in the reaction for $24 \mathrm{~h}$, the yield was calculated in the reaction stopped $(48 \mathrm{~h})$. d, The initial rate was based on the reaction after $3 \mathrm{~h}$.

From Table 3., the acyl group on primary position is the only site for C. rugosa lipase-catalyzed ethanolysis, and the catalytic efficiencies are largely influenced by the orientation of substituded groups as well as the chain length of acyl groups. Generally, the $\alpha$-conformers are better substrates than the $\beta$-conformers, which was similar to being reacted in phosphate buffer (Table 1.). The substrates with propanoyl groups are more reactive than with acetyl groups for CRI-catalyzed regioselective ethanolysis reactions. It was worthy to note that the accumulation of $6-\mathrm{OH}$ derivatives of methyl $\beta$ - Dglucopyranoside were largely increased because no migration occured.

\section{Conclusion}

In conclusion, the lipase from Candida rugosa (CRL) is an effective biocatalyst for the regioseletive ethanolysis of peracylated methyl glycopyranosides in nonpolar organic solvents. The CRI -catalyzed ethanolysis of peracylated methyl glycopyranosides can be not only efficiently but also simply performed in such a solvent system and it is not 
necessary to purify the product by column chromotraphy. From the view of organic synthesis, the suitable regulatory of acyl groups on sugar for enzyme-catalyzed ethanolysis in nonpolar solvent can open another way to promote and modify the enzyme application in carbohydrate chemistry.

\section{References :}

1. (a) Chen, C. S.; Sih, C. J. Angew. Chem. Int. Eng. Ed., 1989, 28, 695.

(b) Klibanov, A. M. Acc. Chem. Res. 1990, 23, 114.

2. (a) Drueckhammer, D. G.; Hennen, W. J.; Pederson, R. L.; Barbas, III, C. F.; Gautheron, C. M.; Krach, T; Wong, C. H. Synthesis. 1991, 499.

(b) Wong, C. H.; Whiteside G. M. Enzymes in Synthetic Organic Chemistry, 1st ed.; Elsevier; New, York, 1994.

3. Parida, S.; Dordick, J. S. J. Am. Chem. Soc. 1991, 113, 2253.

4. (a) Haines, A. H., Adv. Carbohydr. Chem. Biochem., 1976, 33, 11.

(b) Haines, A. H., Adv. Carbohydr. Chem. Biochem., 1981, 39, 13.

5. (a) Sweers, H.M.; Wong, C.H., J. Am. Chem. Soc. 1986, 108, 6421.

(b) Chang, K.Y.; Wu, S.H.; Wang, K.T., Carbohydr. Res., 1991, 222, 121.

(c) Chang, K.Y.; Wu, S.H.; Wang, K.T., Carbohydr. Res., 1991, 222, 121.

(d) Chang, K.Y.; Wu, S.H.; Wang, K.T., J. Carbohydr. Chem., 1991, 10, 251.

(e) Wu, S. H.; Ong, G. T.; Hsiao, K. Y.; Wang, K. T. J. Chin. Chem. Soc. 1992, 39, 675.

(f) Ong, G.T.; Chang, K.Y.; Wu, S.H.; Wang, K.T., Carbohydr. Res., 1993, 241, 327.

(g) Hsiao, K.F.; Wu, S.H.; Wang, K.T., Bioorg. Med. Chem. Lett .1993, 3, 2125.

(h) Ong, G.T.; Chang, K.Y.; Wu, S.H.; Wang, K.T., Carbohydr. Res., 1994, 265, 311.

(i) Chen, H. P.; Hsiao, K.F.; Wu, S.H.; Wang, K.T., Biotechnol. Lett. 1995, 17, 305.

6. (a) Hene, W. J.; Sweers, H. M.; Wang, Y.-F; Wong, C.H. J. Org. Chem. 1988, 53, 4939.

(b) Holla, W. Angew. Chem. Int. Engl. Ed. 1989, 28, 220.

7. (a) Riva, S.; Chopineau, J.; Kieboom, A.P.G ; A.M. Klibanov, J. Am. Chem. Soc. 1988, 110,584 .

(b) Therisod, M.; Klibanov, A.M. J. Am. Chem. Soc. 1987, 109, 3977.

8. Hsiao, K.F.; Lin, H. J.; Leu, D. L.; Wu, S.H.; Wang, K.T., Bioorg. Med., Chem. Lett $.1994,4,1629$.

9. Parida, S.; Dordick, J. S. J. Org. Chem. 1993, 58, 3238.

10. (a) Laane, C.; Tramper, J.; Lilly, M. D. Biocatalysis in Organic Media, ed.; Elesevier: Amsterdam, 1986.

(b) Chen, C. H.; Wu, S. H.; Girdaukas, G.; Sih, C. J. J. Am. Chem. Soc. 1987, 109, 2812.

(c) Theisen, P. D.; Heathcock, C. H. J. Org. Chem. 1988, 53, 2374.

11. Stamatis, H.; Xenakis, A.; Provelegiou, M.; Kolisis, F. N. Biotehnolo. Bioeng. 1993, 42, 103.

12. Liu, K. K. C.; Nozaki, K.; Wong, C. H. Biocatalysis 1990, 3, 169.

13. From the chromatograms, only the $6-\mathrm{OH}$ derivatives and the corresponding ethyl ester were new-observed. 